\title{
MANAJEMEN BUDIDAYA IKAN LELE DUMBO (Clarias gariepinus) DI KAMPUNG LELE, KABUPATEN BOYOLALI, JAWA TENGAH
}

\author{
Willy Nofian Muhammad dan Septyan Andriyanto \\ Pusat Penelitian dan Pengembangan Perikanan Budidaya \\ Jl. Ragunan 20, Pasar Minggu, Jakarta Selatan 12540 \\ E-mail: willynofian@gmail.com; septian08@yahoo.com
}

\begin{abstract}
ABSTRAK
Meningkatnya kebutuhan masyarakat terhadap ikan lele konsumsi membuat pembudidaya lele kesulitan dalam memenuhi kebutuhan tersebut. Desa Tegalrejo, salah satu desa di Kabupaten Boyolali pada tahun 2006 dinobatkan sebagai "Kampung Lele" oleh Gubernur Jawa Tengah dikarenakan mayoritas penduduknya melakukan usaha budidaya dan pengolahan lele. Namun produksinya hanya mampu memenuhi sebesar 30\% dari seluruh permintaan pasar. Budidaya ikan lele tidak hanya teknologi yang dibutuhkan, namun juga dukungan masyarakat dan pemerintah terkait manajemen budidaya ikan lele sesuai Standar Operasional Prosedur (SOP). Dalam rangka menunjang hal tersebut dilakukan penelitian yang bertujuan untuk mengetahui aspek manajemen budidaya ikan lele dumbo (Clarias gariepinus) meliputi perencanaan produksi kawasan, sistem kemitraan, pengorganisasian, dan pelaksanaan berupa manajemen pemeliharaan, produksi, serta analisis usahanya. Hasil pengamatan menunjukkan kegiatan perencanaan produksi kawasan dapat dikatakan baik, dilihat dari keberlanjutan produk, serta adanya kerjasama yang baik antara pembudidaya, supplier, dan kelompok budidaya. Begitu pula dalam aspek teknis budidaya, di mana seluruh kegiatan mengikuti SOP yang telah dibuat oleh kelompok dengan volume produksi mencapai 10 ton/hari. Sehingga untuk dapat memenuhi kebutuhan pasar, serta peningkatan produksi dapat dilakukan dengan memanfaatkan lahan yang tidak digunakan untuk dijadikan lahan budidaya.
\end{abstract}

KATA KUNCI : manajemen budidaya, ikan lele Clarias gariepinus, Boyolali

\section{PENDAHULUAN}

Ikan lele dumbo (Clarias gariepinus) merupakan salah satu ikan ekonomis penting air tawar yang telah banyak dibudidayakan baik secara tradisional maupun secara intensif. Ikan lele dumbo memiliki banyak kelebihan dengan pertumbuhannya lebih cepat dibandingkan dengan ikan lele lokal dan dapat hidup dalam kondisi perairan yang rendah kandungan oksigennya (Suyanto, 2007).

Dewasa ini kebutuhan ikan lele meningkat, seiring dengan meningkatnya pertumbuhan penduduk dan permintaan akan ikan lele tersebut. Kebutuhan ikan lele konsumsi untuk Jakarta, Bogor, Depok, Tangerang, dan Bekasi (Jabodetabek) mencapai 150 ton/hari, sedangkan Yogyakarta kebutuhannya mencapai 30 ton/hari. Kebutuhan tersebut akan terus meningkat dengan meningkatnya permintaan akan ikan lele ukuran konsumsi.

Pada tahun 2006, Desa Tegalrejo yang merupakan salah satu desa di Kabupaten Boyolali dinobatkan Gubernur Jawa Tengah sebagai "Kampung Lele" dikarenakan mayoritas penduduknya melakukan usaha budidaya dan pengolahan ikan lele. Hingga saat ini usaha pembudidayaan ikan lele pada "Kampung Lele" semakin berkembang, terlihat dari luasan kolam budidaya ikan lele telah mencapai 17 ha yang terdiri atas \pm 1.600 kolam budidaya dan masih produktif dalam kegiatan pembesaran ikan lele (Gambar 1).

"Kampung Lele" sebagai salah satu suatu kawasan minapolitan yang bidang usahanya meliputi pembudidayaan dan pengolahan ikan lele, hingga saat ini tingkat produksinya masih belum mampu memenuhi permintaan pasar. Sehingga diperlukan dukungan dari masyarakat sekitar dan pemerintah dalam penerapan manajemen budidaya, serta manajemen usaha yang baik. Dalam rangka menunjang hal 


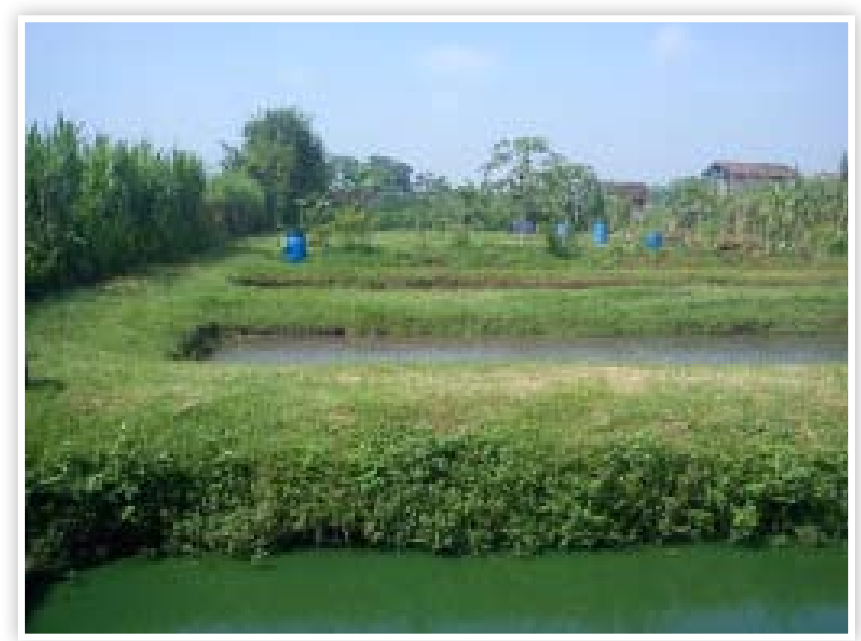

Gambar 1. Kolam budidaya ikan lele, Clarias gariepinus di "Kampung Lele", Kabupaten Boyolali, Jawa Tengah

tersebut maka dilakukan pengamatan yang bertujuan untuk mengetahui aspek manajemen budidaya ikan lele dumbo (Clarias gariepinus) meliputi perencanaan produksi kawasan, sistem kemitraan, pengorganisasian, dan pelaksanaan berupa manajemen pemeliharaan, produksi, serta analisis usahanya.

\section{METODOLOGI}

Kegiatan dilakukan bertempat di "Kampung Lele" Desa Tegalrejo Kecamatan Sawit Kabupaten Boyolali. Data primer yang dikumpulkan diperoleh dengan cara mengikuti seluruh kegiatan budidaya ikan lele dumbo (Clarias gariepinus) yang dilakukan di "Kampung Lele", baik berupa pengamatan, pengukuran, serta wawancara langsung. Pengamatan aspek teknis budidaya dilakukan pada 10 kolam milik pembudidaya ikan lele. Sedangkan data sekunder diperoleh dari laporan kegiatan kelompok budidaya, laporan-laporan instansi atau dinas terkait, dan studi literatur. Data yang diperoleh kemudian dianalisis dengan menggunakan metode deskriptif dan metode kuantitatif.

\section{HASIL DAN BAHASAN}

\section{Perencanaan Produksi Kawasan}

Kegiatan perencanaan produksi kawasan yang terdapat di "Kampung Lele" dengan total lahan yang ada seluas 25 ha dan yang telah dimanfaatkan untuk kolam budidaya lele seluas 17 ha dapat dikatakan baik, hal ini dibuktikan oleh keberlanjutan produk yang tetap terjaga yaitu dengan produksi 10 ton/harinya. Hal tersebut dikarenakan adanya kerja sama yang baik antara pembudidaya, supplier, dan kelompok budidaya. Di mana pembudidaya menyediakan tenaga dan kolam, supplier yang menyediakan sarana serta prasarana yang dibutuhkan, sedangkan kelompok yang menyediakan informasi tentang pasar. Sesuai pernyataan Manullang (2001) perlu adanya kerja sama yang baik dalam merancang suatu perencanaan yang baik.

\section{Sistem Kemitraan}

Sistem kemitraan yang digunakan dalam kegiatan budidaya di "Kampung Lele" berupa sistem kekerabatan yang memberikan keuntungan bagi kedua belah pihak pembudidaya. Pihak pertama yang memiliki kolam akan mendapatkan keuntungan dengan menyediakan sarana dan prasarana berupa benih, pakan, dan mesin diesel, sedangkan pihak kedua memperoleh keuntungan dengan melakukan pemeliharaan pada kolam, serta sarana dan prasarana yang disediakan pihak pertama. Keuntungan dibagi sesuai dengan perjanjian yang telah disepakati sebelumnya oleh kedua pihak dan memegang prinsip saling menguntungkan. Bentuk sistem kemitraan dalam kegiatan budidaya ikan lele di "Kampung Lele" dengan menggunakan sistem kekerabatan dapat dicontohkan sebagai berikut:

Apabila pembudidaya A mengusahakan modal bibit, pakan, dan kolam sedang pembudidaya B mengusahakan pemeliharaannya saja, mereka dapat membagi keuntungan dengan porsi sebagai berikut: pembudidaya A mendapat $3 / 4$ bagian dari keuntungan dan pembudidaya $B$ mendapat $1 / 4$ keuntungan.

Apabila pembudidaya A mengusahakan modal bibit dan kolam sedang pembudidaya B mengusahakan kolam dan pemeliharaan, mereka dapat membagi keuntungan sebagai berikut: pembudidaya $A$ mendapat $1 / 2$ bagian dari keuntungan dan pembudidaya $B$ juga mendapat $1 / 2$ bagian keuntungan.

Sesuai pernyataan Darseno (2010) bahwa sistem kekerabatan dengan bagi hasil dapat memberikan keuntungan bagi kedua belah pihak. 


\section{Pengorganisasian}

Organisasi atau kelembagaan di "Kampung Lele" hanya terdapat dalam satu wadah pokdakan bernama "Karya Mina Utama”, yang beranggotakan 94 orang dan seluruh anggotanya memiliki pekerjaan pokok sebagai pembudidaya ikan lele. Beberapa keuntungan yang diperoleh pembudidaya dari organisasi "Karya Mina Utama" yaitu kemudahan dalam pembelian pakan, serta benih ikan lele dumbo hingga kemudahan dalam penjualan hasil panen. Sehingga mampu mengurangi cost atau biaya operasional, serta keuntungan yang diperoleh pembudidaya akan lebih maksimal.

Awalnya sumber permodalan "Karya Mina Utama" berasal dari bantuan-bantuan langsung pemerintah. Dana tersebut bersifat lunak dan revolving yang dibagikan secara merata kepada seluruh anggota yang memiliki kolam. Melalui kelompok "Karya Mina Utama" seluruh proses budidaya dikelola secara terorganisir dan transparan, sehingga keuntungan yang diperoleh dapat dimanfaatkan anggota kelompok untuk biaya operasional berikutnya, serta tidak lagi bergantung dari bantuan pemerintah ataupun pinjaman dari perbankan.

Pembagian tugas dalam organisasi merupakan hal yang perlu dilakukan dalam mencapai tujuan atau target yang telah ditetapkan agar tidak terjadi tumpang tindih pekerjaan. Begitupula yang dilakukan pokdakan "Karya Mina Utama" di mana dalam pembagian tugas yang ditetapkan kelompok terbagi dalam beberapa aspek di antaranya: penggunaan teknologi budidaya, penanggulangan hama dan penyakit, pemasaran, dan produksi. Pembagian tugas dilakukan berdasarkan jabatan yang diemban dalam struktur organisasi/kelembagaan pokdakan "Karya Mina Utama" sebagai berikut:

a. Penasehat, bertugas sebagai narasumber dalam kegiatan rapat anggota, serta pihak penengah apabila terjadi masalah.

b. Ketua, bertugas mengawasi jalannya seluruh kegiatan yang diselenggarakan, serta menjadi pengawas dan ketua dalam rapat anggota.

c. Bendahara, bertugas memegang kendali atas pemasukan dan pengeluaran kelompok beserta pembukuannya. d. Sekretaris, bertugas untuk mengemas dan menyampaikan informasi dari setiap seksi juga informasi tentang rapat anggota kelompok.

e. Seksi Penerapan Teknologi, bertugas antara lain: menyiapkan teknologi budidaya yang spesifikasinya cocok untuk kelompok; mencari informasi perkembangan teknologi sebagai acuan; dan menyampaikan informasi, inovasi baru, dan mengemas teknologi kepada anggota.

f. Seksi Sarana Produksi, memiliki tugas di antaranya; mengelola inventaris kelompok dan penggunaanya agar dapat berguna seefisien mungkin; menyiapkan sistem penggunaan dan aturan-aturan penggunaannya; merencanakan dan mengembangkan sarana dan perlengkapan untuk kesejahteraan anggota.

g. Seksi Pemasaran, bertugas untuk: mencari terobosan pasar baru untuk menghadapi perkembangan di masa depan; mengatur dan membagi distribusi pasar agar tidak terjadi tumpang tindih; serta mengkoordinasikan kebutuhan hasil produksi dengan para supplier.

h. Seksi Pengendalian Hama dan Penyakit, memiliki tugas guna melakukan: monitoring perkembangan ikan dan lingkungan; serta mencari terobosan dalam pengendalian dan pengobatan hama dan penyakit ikan.

Pembagian kerja yang dilakukan oleh kelompok "Karya Mina Utama” sudah dilakukan dengan baik. Hal ini dikarenakan pembagian kerja dilakukan dalam seksi atau bagian-bagian kerja yang dibutuhkan. Pembagian kerja tersebut sesuai dengan keahlian dan kapasitas dari setiap seksi atau bagian tersebut. Hal tersebut sesuai dengan Manullang (2001) yang menyatakan bahwa pembagian kerja adalah keharusan, sebab tanpa adanya pembagian kerja kemungkinan terjadinya tumpang tindih tugas menjadi amat besar.

\section{Pelaksanaan}

Pelaksanaan kegiatan yang dilakukan di "Kampung Lele" seluruhnya mengikuti Standar Operasional Prosedur (SOP) yang telah dibuat oleh ketua kelompok, dengan pendampingan dari penyuluh perikanan yang berada 
Tabel 1. Dosis pemberian pakan dalam budidaya ikan lele dumbo di "Kampung Lele"

\begin{tabular}{cc}
\hline Dosis pemberian & Waktu pemberian \\
\hline $2 \%$ x biomassa ikan dalam kolam & Awal bulan (30 hari pemeliharaan) \\
$2 \%$ x biomassa ikan dalam kolam & Awal bulan kedua (30 hari pemeliharaan) \\
$3 \%$ x biomassa ikan dalam kolam & Awal bulan ketiga sampai dengan panen (30-60 hari pemeliharaan) \\
\hline
\end{tabular}
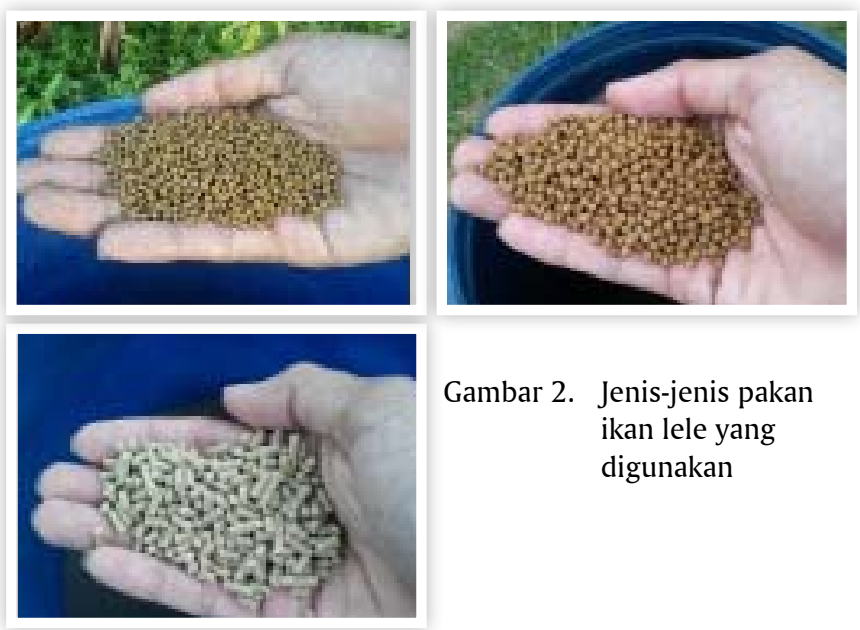

Gambar 2. Jenis-jenis pakan ikan lele yang digunakan di bawah pemda setempat/kecamatan yang terdiri atas manajemen pemeliharaan, produksi, dan pemasaran, serta analisis usahanya. Seperti pernyataan Howerton (2001) bahwa untuk mendapatkan hasil yang baik dalam kegiatan budidaya perlu diterapkan manajemen yang baik.

\section{Manajemen pemeliharaan}

Pembudidayaan ikan lele, Clarias gariepinus di "Kampung Lele" seluruhnya mengikuti Standar Operasional Prosedur (SOP), sehingga seluruh aspek teknis budidaya telah mengikuti standar manajemen budidaya yang telah ditetapkan. Beberapa tahapan aspek teknis budidaya tersebut yaitu persiapan kolam pemeliharaan, pengelolaan benih ikan lele dumbo, pengelolaan pakan, manajemen/ pengelolaan kualitas air, manajemen kesehatan ikan, serta panen lele konsumsi.

Sumber air yang digunakan sebagai media pemeliharaan berasal dari mata air Gunung Merapi, yang mengalir melalui sungai yang melewati lokasi budidaya. Air yang mengalir langsung digunakan sebagai media budidaya tanpa adanya treatment apapun. Kolam budidaya yang digunakan berbentuk persegi panjang berukuran $4 \mathrm{~m}$ x 15 $\mathrm{m} \times 1 \mathrm{~m}$ atau seluas $60 \mathrm{~m}^{2}$ tiap kolamnya, yang di dasarnya terdapat caren dan catching area yang bertujuan untuk mempermudah pembudidaya dalam pengeringan kolam serta pemanenan.

Persiapan kolam pemeliharaan ikan lele diawali dengan pengeringan air, pengangkatan lumpur kolam, pengeringan tanah dasar (dibantu sinar matahari selama 3-5 hari), pengisian air kolam (tinggi air $1 \mathrm{~m}$ ), dilanjutkan pemupukan air kolam (dengan memanfaatkan kotoran ayam dengan dosis $30 \mathrm{~kg} / 60 \mathrm{~m}^{2}$ atau $500 \mathrm{mg} / \mathrm{L}$ ). Setelah pemupukan, kolam dibiarkan selama 3 hingga 5 hari untuk menumbuhkan plankton yang digunakan sebagai pakan awal ketika benih ditebar.

Benih lele diperoleh dengan membeli dari Unit Pembenihan Rakyat (UPR) di Tulungagung dan Kediri. Setiap harinya total kebutuhan benih ikan lele di "Kampung Lele" sebesar 150.000-200.000 ekor dengan harga Rp 110,- -Rp 120,- per ekor dengan kepadatan benih dalam satu kolam adalah $250 \mathrm{ekor} / \mathrm{m}^{2}$. Ukuran benih yang digunakan berkisar 7-8 cm dan harus memiliki ciri-ciri: ukurannya seragam, tidak cacat, gerakannya aktif, dan tidak ada luka pada tubuh.

Pakan komersil yang digunakan dalam budidaya didapatkan dari pabrik pakan di Bogor (Gambar 2). Total kebutuhan pakan/kolam/siklusnya mencapai $1.380 \mathrm{~kg}$ dengan dosis pemberian pakan seperti dalam Tabel 1 .

Hasil pengukuran parameter kualitas air kolam selama pemeliharaan secara umum memperlihatkan kondisi yang layak bagi ikan lele, Clarias gariepinus dengan suhu antara $26^{\circ} \mathrm{C}-33^{\circ} \mathrm{C}$, derajat keasaman $(\mathrm{pH})$ berkisar $5,8-7,3$; kandungan oksigen terlarut sebesar (DO) 5-12 mg/L, kadar amoniak dengan kisaran 0,5-2 mg/L, serta kandungan nitrit antara $0-0,2 \mathrm{mg} / \mathrm{L}$.

Pengendalian dan pencegahan hama dan penyakit yang dilakukan di "Kampung Lele" umumnya dilakukan secara visual dengan melihat aktivitas benih setiap harinya, nafsu makan hingga kondisi fisik benih. Sedangkan kegiatan 

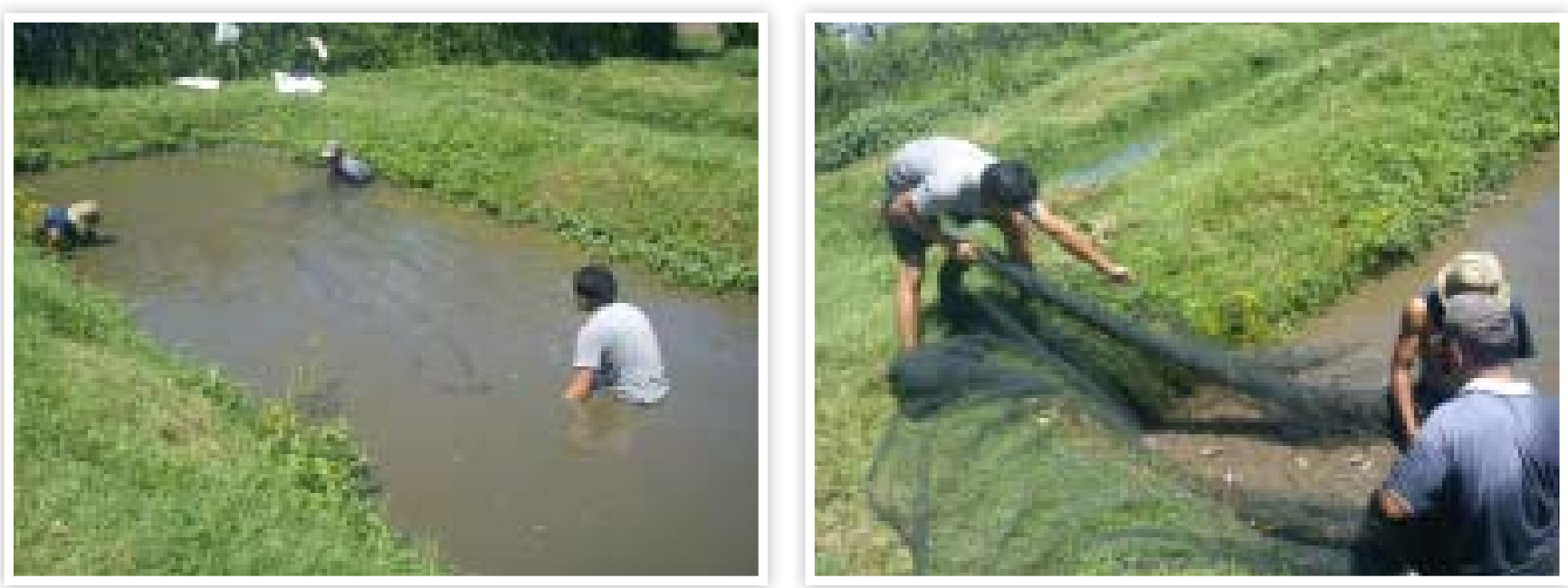

Gambar 3. Proses pemanenan ikan lele dumbo, Clarias gariepinus pada salah satu kolam di "Kampung Lele"

pencegahan yang dilakukan dengan sanitasi lahan dan lingkungan, pengelolaan air, serta pengaturan pakan.

Kegiatan pemanenan ikan lele dilakukan setelah pemeliharaan selama 3-4 bulan dengan ukuran lele konsumsi 7-12 (artinya dalam $1 \mathrm{~kg}$ ikan terdapat 7 hingga 12 ekor) (Gambar 3).

\section{Produksi Ikan Lele dan Pemasaran}

Volume produksi ikan lele ukuran konsumsi hasil budidaya di "Kampung Lele" tiap harinya mencapai 10 ton dengan total luas kolam budidaya 17 ha. Produktivitas rata-rata per kolam berukuran $60 \mathrm{~m}^{2}$ adalah 1 ton per siklus pemeliharaan atau 4 ton per tahunnya. Sehingga produktivitas dari seluruh kolam budidaya (sebanyak 1.600 kolam) mencapai 6.400 ton/tahun atau per hektar mencapai 376 ton/tahunnya, dengan nilai konversi pakan atau FCR (Food Convertion Ratio) berkisar 1,10-1,16. Produktivitas tersebut dapat tercapai tiap tahunnya dengan persiapan kolam yang pendek 6-10 hari, serta penerapan SOP budidaya ikan lele yang baik oleh setiap pembudidaya. Persentase rata-rata kematian ikan dari seluruh kolam pengamatan sebesar 1,55\% sedangkan untuk sintasannya berkisar antara 98,12\%-98,64\%. Tingginya sintasan dikarenakan penanganan yang baik mulai dari pengangkutan, penebaran benih hingga pemanenan. Data hasil pengamatan pertumbuhan, serta sintasan ikan lele dumbo pada 10 kolam pengamatan tersaji pada Tabel 2.

Pertumbuhan panjang dan bobot badan ikan lele dumbo yang diamati pada 10 kolam pemeliharaan menunjukkan pola peningkatan selama masa pemeliharaan

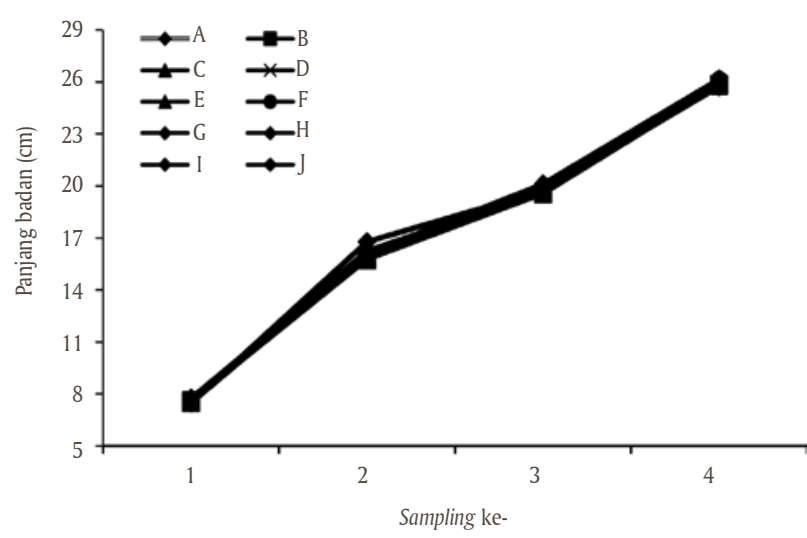

Gambar 4. Pola pertumbuhan panjang tubuh ikan lele dumbo Clarias gariepinus

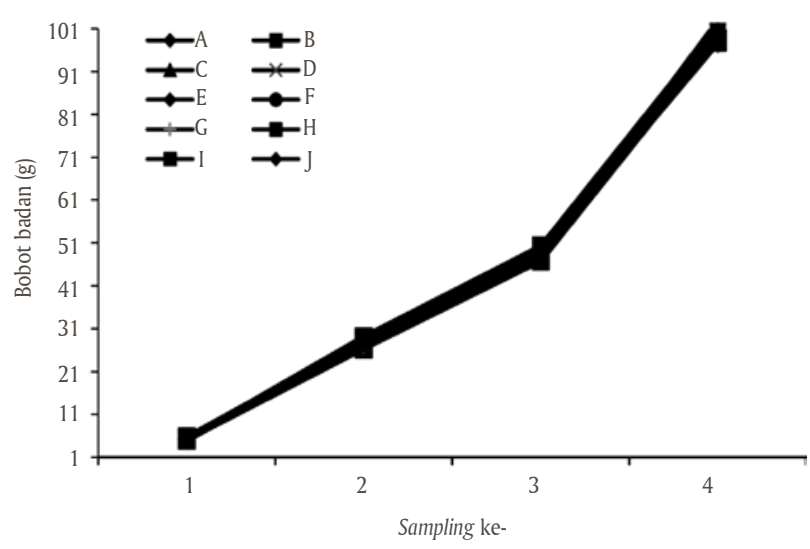

Gambar 5. Pola pertumbuhan bobot badan ikan lele dumbo Clarias gariepinus 
Tabel 2. Hasil pengamatan panjang dan bobot badan ikan lele dumbo, Clarias gariepinus

\begin{tabular}{|c|c|c|c|c|c|c|c|c|}
\hline \multirow{2}{*}{$\begin{array}{c}\text { Kolam } \\
\text { pemeliharaan }\end{array}$} & \multicolumn{4}{|c|}{ Sampling berdasarkan panjang badan $(\mathrm{cm})$} & \multicolumn{4}{|c|}{ Sampling berdasarkan bobot badan (g) } \\
\hline & 1 & 2 & 3 & 4 & 1 & 2 & 3 & 4 \\
\hline A & $7,68 \pm 0,52$ & $16,18 \pm 1,54$ & $19,73 \pm 1,53$ & $25,75 \pm 1,60$ & $5,11 \pm 0,85$ & $27,76 \pm 6,77$ & $47,65 \pm 9,73$ & $100,24 \pm 16,92$ \\
\hline B & $7,75 \pm 0,57$ & $16,60 \pm 1,31$ & $20,13 \pm 1,26$ & $26,18 \pm 1,45$ & $5,34 \pm 0,98$ & $29,08 \pm 6,14$ & $50,21 \pm 8,76$ & $101,87 \pm 15,23$ \\
\hline $\mathrm{C}$ & $7,50 \pm 0,61$ & $16,78 \pm 1,37$ & $19,75 \pm 1,16$ & $26,18 \pm 1,55$ & $5,69 \pm 0,72$ & $28,34 \pm 7,00$ & $49,46 \pm 10,64$ & $97,93 \pm 16,19$ \\
\hline $\mathrm{D}$ & $7,70 \pm 0,55$ & $16,50 \pm 1,43$ & $19,80 \pm 1,42$ & $26,00 \pm 1,41$ & $5,70 \pm 0,85$ & $28,91 \pm 6,15$ & $47,46 \pm 9,65$ & $99,94 \pm 16,64$ \\
\hline $\mathrm{E}$ & $7,60 \pm 0,66$ & $16,10 \pm 1,23$ & $19,80 \pm 1,49$ & $26,08 \pm 1,62$ & $5,37 \pm 0,73$ & $28,16 \pm 6,62$ & $48,88 \pm 8,12$ & $98,32 \pm 16,49$ \\
\hline $\mathrm{F}$ & $7,50 \pm 0,40$ & $16,03 \pm 1,22$ & $20,00 \pm 1,28$ & $26,05 \pm 1,32$ & $5,19 \pm 0,54$ & $27,37 \pm 6,51$ & $48,54 \pm 5,27$ & $97,63 \pm 15,45$ \\
\hline G & $7,48 \pm 0,50$ & $16,03 \pm 1,41$ & $19,73 \pm 1,53$ & $25,75 \pm 1,60$ & $4,93 \pm 0,76$ & $27,36 \pm 6,14$ & $47,65 \pm 9,73$ & $100,24 \pm 16,92$ \\
\hline $\mathrm{H}$ & $7,65 \pm 0,56$ & $15,98 \pm 1,55$ & $19,80 \pm 1,44$ & $25,90 \pm 1,41$ & $5,09 \pm 0,88$ & $26,96 \pm 6,68$ & $48,12 \pm 9,14$ & $101,31 \pm 15,49$ \\
\hline I & $7,58 \pm 0,59$ & $15,78 \pm 1,57$ & $19,58 \pm 1,39$ & $25,85 \pm 1,46$ & $5,05 \pm 0,91$ & $26,30 \pm 6,62$ & $46,84 \pm 8,94$ & $98,61 \pm 20,20$ \\
\hline $\mathrm{J}$ & $7,55 \pm 0,56$ & $16,25 \pm 1,32$ & $19,73 \pm 1,53$ & $26,05 \pm 1,41$ & $5,02 \pm 0,85$ & $28,13 \pm 5,83$ & $47,70 \pm 9,74$ & $102,78 \pm 16,05$ \\
\hline
\end{tabular}
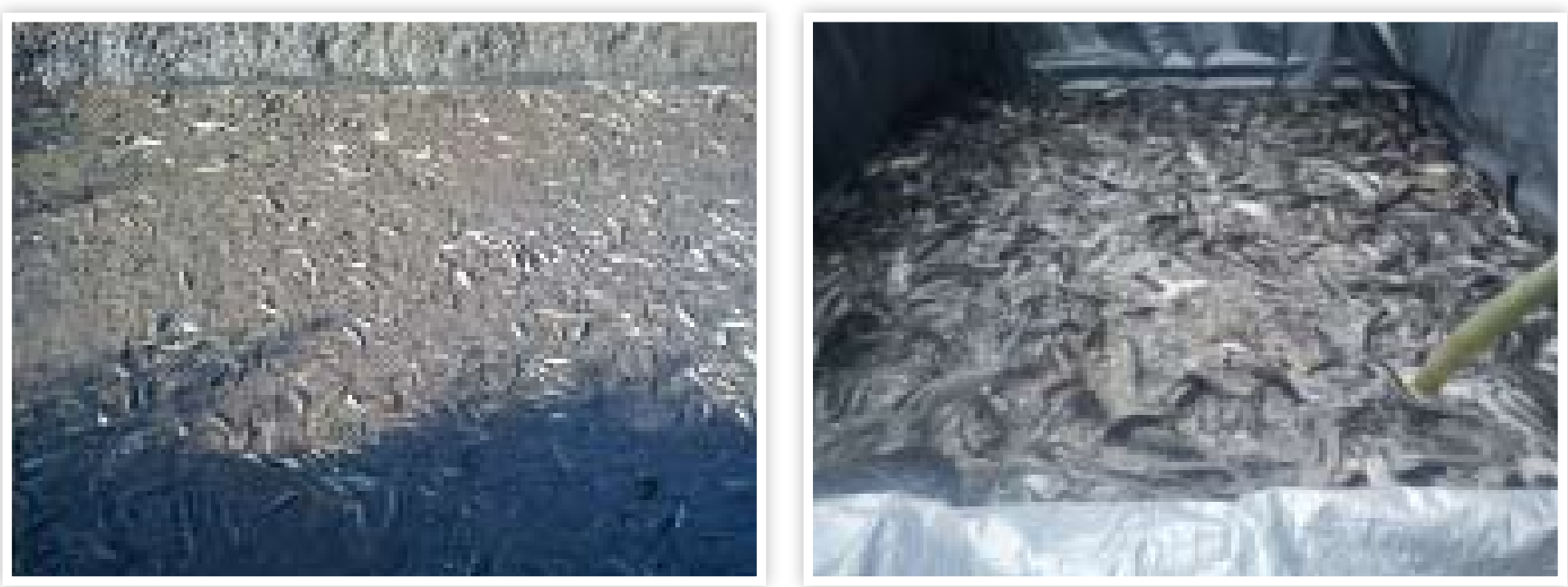

Gambar 4. Produksi ikan lele dumbo dalam satu kolam budidaya di “Kampung Lele” (kiri); dan ikan lele konsumsi hasil panen siap untuk dipasarkan (kanan)

dengan ukuran yang seragam. Hal ini dikarenakan selama masa pemeliharaan menggunakan pakan dengan kandungan nutrisi yang tinggi mencapai $32 \%$, serta metode pemberian pakan dengan menebar pakan secara merata ke seluruh bagian kolam.

Seluruh produksi ikan lele konsumsi dari "Kampung Lele" (Gambar 4) dipasarkan ke Yogyakarta, namun ternyata dari total produksi ikan lele per harinya (10 ton) belum mampu memenuhi total kebutuhan ikan lele di Yogyakarta sebesar 30 ton/hari.

\section{Analisis Usaha}

Penghitungan analisis finansial dihitung untuk kurun waktu lima tahun yang dipergunakan dalam kegiatan budidaya ikan lele di "Kampung Lele". Dasar penghitungan yang digunakan menggunakan data total volume produksi ikan lele per hari, total biaya investasi, dan total biaya operasional per total luasan lahan budidaya (1.600 kolam seluas 17 ha) dengan rincian seperti pada Lampiran 1.

Hasil penghitungan Revenue Cost Ratio (R/C Ratio) diperoleh nilai 1,05 yang menunjukkan bahwa dalam Rp 
1,- yang diinvestasikan akan memperoleh keuntungan Rp 1,05 ,-. Sehingga usaha ini layak dijalankan karena nilai B/C Ratio yang diperoleh lebih dari 1. Sesuai pernyataan Soeharto (1997) bahwa B/C rasio lebih dari 1 maka usaha tersebut layak untuk dilanjutkan.

$$
\begin{aligned}
\mathrm{P} & =\frac{\text { Total investasi }}{\text { Kas masuk bersih }} \times 1 \text { periode } \\
& =\frac{3.542 .000 .000}{3.400 .740 .000} \times 1 \text { tahun } \\
& =1,04 \text { tahun }
\end{aligned}
$$

Payback Periode (PP) dari penghitungan diperoleh nilai sebesar 1,04 tahun artinya jangka waktu pengembalian investasi/modal adalah 1 tahun, 1 bulan, dan 18 hari.

\section{KESIMPULAN DAN SARAN}

Penerapan fungsi-fungsi manajemen budidaya di "Kampung Lele" yang terdiri atas perencanaan produksi kawasan, sistem kemitraan, pengorganisasian, serta pelaksanaan terkait manajemen pemeliharaan, produksi, serta analisis usahanya secara umum telah berjalan dengan baik. Hal tersebut dapat dilihat dari keberlanjutan produksi per harinya yang mencapai 10 ton, serta adanya kerja sama yang saling menguntungkan antara pembudidaya, supplier, dan kelompok budidaya.

Dalam upaya memenuhi kebutuhan pasar, serta peningkatan produksi ikan lele di "Kampung Lele" dapat dilakukan dengan memanfaatkan lahan yang tidak digunakan untuk dijadikan lahan budidaya.

\section{DAFTAR ACUAN}

Darseno. 2010. Budidaya \& bisnis lele. Agro Media Pustaka. Jakarta.

Howerton, R. 2001. Best management practices for Hawaiian aquaculture. University of Hawaii Sea Grant Extension Services. Center for Tropical and Subtropical Aquaculture. Publication No. 148, Hawaii.

Manullang, M. 2001. Dasar-dasar manajemen. Gadjah Mada University Press. Yogyakarta.

Soeharto, I. 1997. Manajemen proyek dari konseptual sampai operasional. Erlangga. Jakarta.

Suyanto, R. 2007. Budidaya ikan lele. Penebar Swadaya. Jakarta. 
Lampiran 1. Analisis usaha budidaya lele

A. Investasi

Sarana:

- Kolam 1.600 buah @ Rp 2.000.000,-

Rp 3.200.000.000,-

- Mesin diesel 20 buah @ Rp 8.000.000,-

Rp 160.000.000,-

- Selang mesin diesel 20 buah @ Rp 350.000,-

Rp 7,000.000,-

- Ember plastik 1.600 buah @ Rp 30.000,- $\quad$ Rp 48.000.000,-

- Seser 1.600 buah @ Rp 75.000,- Rp 120.000.000,-

- Hapa 20 buah @ Rp 350.000,- $\quad$ Rp 7.000.000,-

Total investasi Rp $\quad$ R.542.000.000,-

B. Biaya tetap (1 tahun)

1. Penyusutan:

- $\quad$ Kolam 1/5 x Rp 3.200.000.000,-

Rp 640.000.000,-

- Mesin diesel 1/5 x Rp 160.000.000,-

- Selang mesin diesel 1/5 x Rp 7.000.000,-

Rp 32.000.000,-

- Ember plastik 1/5 x Rp 48.000.000,-

Rp 1.400.000,-

- $\quad$ Seser 1/3 x Rp 120.000.000,-

Rp 9.600.000,-

- $\quad$ Hapa 1/3 x Rp 7.000.000,-

Rp 40.000.000,-

Total penyusutan

$\begin{array}{lr}\text { Rp } & 2.333 .333,- \\ R p & 725.333 .333,-\end{array}$

2. Tenaga kerja 94 orang x 12 bulan @ Rp 2.500.000,- $\quad$ Rp 2.820.000.000,-

3. Biaya perawatan alat

Total biaya tetap

$\begin{array}{ll}\text { Rp } & 354.200 .000,- \\ R p & 3.899 .533,333,-\end{array}$

C. Biaya variabel (1 tahun)

1. Benih lele 96.000.000 ekor @ Rp 120,- $\quad$ Rp 11.520.000.000,-

2. Pakan:

- SNA-2 192.000 kg @ Rp 7.000,-

Rp 1.344.000.000,-

- SNA-3 2.880.000 kg@ Rp 6.800,-

Rp 19.584.000.000,-

- Tenggelam 5.760.000 kg@ Rp 5.800,-

Rp 33.408.000.000,-

3. Pupuk kandang 192.000 kg@ Rp 300,- $\quad$ Rp 57.600.000,-

4. Solar16.000 L @ Rp 4.500,-

Rp 72.000.000,

Total biaya variabel

Rp 65.985.600.000,-

D. Total biaya operasional
1. Biaya tetap
Rp 3.899.533.333,-
2. Biaya variabel
Rp 65.985.600.000,-
Total biaya operasional

Rp 69.885.133.333,-


E. Total penerimaan (1 tahun)

- Hasil panen 6.400.000 kg @ Rp 11.500,-/kg Rp 73.600.000.000,-

F. Laba bersih (1 tahun)

- Penerimaan

- Total biaya operasional

Rp 73.600.000.000,

- Pajak pendapatan

Rp 69.885.133.333,-

Total laba bersih

$\begin{array}{ll}\operatorname{Rp} & 1.039 .460 .000,- \\ \operatorname{Rp} & 2.675 .406 .667,-\end{array}$

G. Cash inflow (kas masuk bersih)

- Laba bersih

\begin{tabular}{lr} 
Rp & $2.675 .406 .667,-$ \\
Rp & $725.333 .333,-$ \\
\hline$R p$ & $3.400 .740 .000,-$
\end{tabular}

H. Analisis R/C dan PP

$\mathrm{R} / \mathrm{C}$ ratio $=\frac{\text { Total penerimaan }}{\text { Total biaya }}$

$=\frac{73.600 .000 .000}{69.885 .133 .333} \quad=1,05$ 
